\title{
A New Soft-Switching Forward DC-DC Converter Operating in Discontinuous
}

\section{Conduction Mode}

\author{
Giorgio Spiazzi, Simone Buso \\ Dept. of Electronics and Informatics - University of Padova (Italy)
}

Via Gradenigo 6/a, 35131 Padova - ITALY

Phone: +39-049-8277525 - Fax: +39-049-8277699

E-mail: giorgio.spiazzi@dei.unipd.i1 simone.buso@dei.unipd.it

\begin{abstract}
The paper presents a simple soft-switching forward DC-DC converter suitable for low power applications. A lossless passive turn-off snubber is employed to provide zero voltage turn off of the switch as well as transformer reset. Moreover, the choice to operate the converter in discontinuous conduction mode (DCM), while providing zero current turn on of the switch, also allows to simplify the topology by eliminating the inductive output filter.

A detailed converter analysis, aimed to highlight advantages and drawbacks of the presented topology, is reported, together with a suitable design procedure. Experimental results are also included to verify the theoretical expectations.
\end{abstract}

\section{INTRODUCTION}

To be competitive, isolated DC-DC converters for low power applications must have reduced size and cost. The former constrain calls for high switching frequency, in order to reduce the reactive component size, while the latter requires to use the minimum number of active switches and magnetic components. However, the increased switching losses, associated to the high switching frequency, ultimately limit the achievable power density, not mentioning the problem of the high EMI level related to high $\mathrm{dv} / \mathrm{dt}$ in the circuit. The use of active snubbers [1] can solve these problems at the expense of an extra switch with associated control, as reported in [2-4].

Cheaper solutions, with less degrees of freedom of course, employ lossless passive snubbers [5], which provide zero voltage turn off, as well as controlled $\mathrm{dv} / \mathrm{dt}$ during the turn off phase. On the other hand, for low power applications, zero current turn on can be easily achieved by discontinuous operation of the converter. In this case, for example, a forward topology can be simplified by removing the inductive output filter, as shown in the proposed converter of Fig. 1: in this case the transformer leakage inductance $L_{d}$ is exploited as the energy transfer element from input to output and only discontinuous operation (DCM) is allowed (in order to ensure a proper core reset).

The following sections include: description of the converter and its operation, derivation of the voltage conversion ratio, derivation of soft-switching boundaries, proposed design procedure, and experimental prototype measurements.

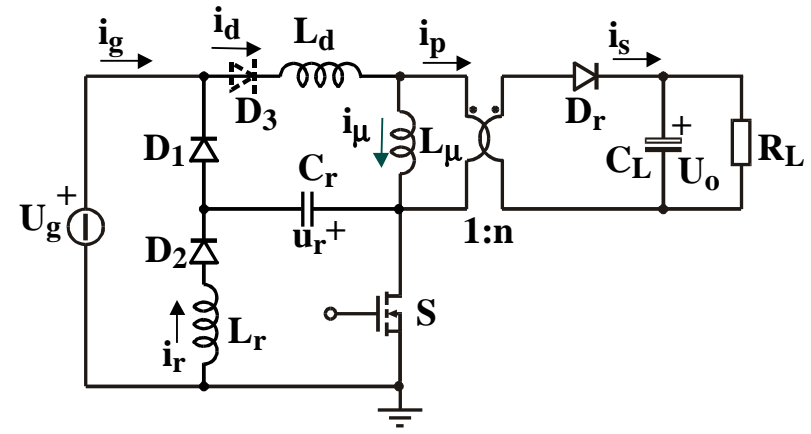

Fig. 1 - Scheme of the proposed soft-switched forward DC-DC converter. (Note that diode $\mathrm{D}_{3}$ can be removed)

\section{CONVERTER DESCRIPTION}

The proposed soft-switching forward DC-DC converter operating in DCM shown in Fig. 1, employs a lossless passive snubber which is made up of snubber capacitor $C_{r}$, inductance $\mathrm{L}_{\mathrm{r}}$, and diodes $\mathrm{D}_{1}, \mathrm{D}_{2}$ and $\mathrm{D}_{3}$ [5]. In particular, diode $\mathrm{D}_{3}$ is initially considered to simplify the converter analysis. However, as it will be explained in the following, it can be removed with a proper snubber design, improving the converter efficiency. According to step-down operation, the output voltage $U_{\text {op }}$ reflected to the transformer primary side must be lower than the input voltage $U_{g}$. The lossless passive snubber provides both zero voltage switch turn off, with a controlled $\mathrm{dv} / \mathrm{dt}$, and transformer reset, while the DCM operation implies zero current switch turn on as well as soft rectifier diode turn off. The converter main waveforms in a switching period are shown in Fig. 2. As we can see, each switching period can be subdivided into five intervals described in the following. In order to simplify the notation, the time origin was implicitly selected at the beginning of each sub-interval.

Interval $T_{01}=T_{1}-T_{0}$ [see Fig. 3a]. At instant $T_{0}$ the switch is turned on under zero current condition causing the turn on of rectifier diode $D_{r}$, if the following condition is satisfied:

$\mathrm{U}_{\mathrm{g}} \frac{\mathrm{L}_{\mu}}{\mathrm{L}_{\mathrm{d}}+\mathrm{L}_{\mu}}>\frac{\mathrm{U}_{\mathrm{o}}}{\mathrm{n}}=\mathrm{U}_{\mathrm{op}}$

where $n=N_{2} / N_{1}$ is the transformer turns ratio 


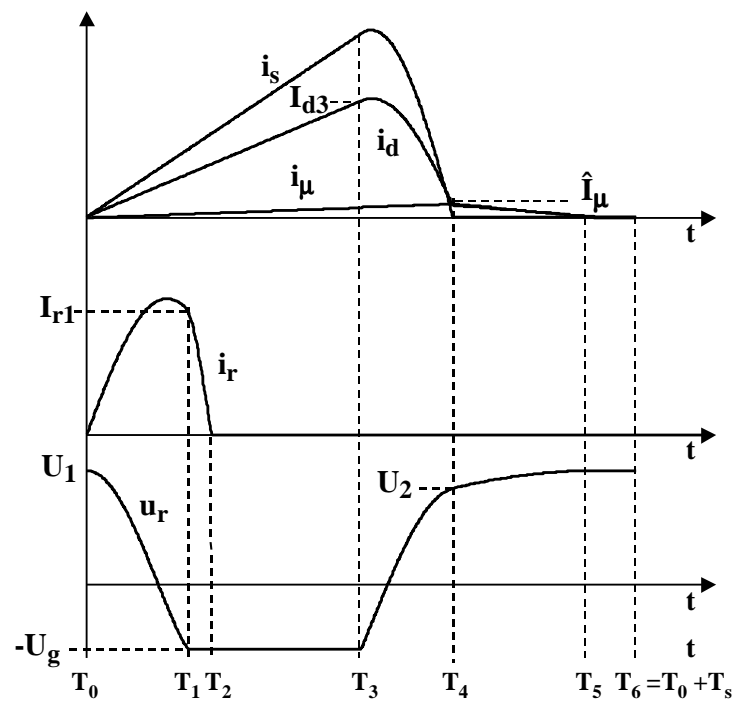

Fig. 2 - Converter main waveforms in a switching period

Both input current $i_{d}$ and magnetizing current $i_{\mu}$ start to increase linearly, as described by the following relations:

$\mathrm{i}_{\mathrm{d}}(\mathrm{t})=\frac{\mathrm{U}_{\mathrm{g}}-\mathrm{U}_{\mathrm{op}}}{\mathrm{L}_{\mathrm{d}}} \mathrm{t}$

$\mathrm{i}_{\mu}(\mathrm{t})=\frac{\mathrm{U}_{\mathrm{op}}}{\mathrm{L}_{\mu}} \mathrm{t}$

At the same time, the snubber capacitor $\mathrm{C}_{\mathrm{r}}$ resonates with inductor $\mathrm{L}_{\mathrm{r}}$ through the loop formed by diode $\mathrm{D}_{2}$ and switch S. Calling $U_{1}$ the initial capacitor voltage, voltage $u_{r}$ and current $i_{r}$ waveforms are given by:

$$
\begin{aligned}
& \mathrm{u}_{\mathrm{r}}(\mathrm{t})=\mathrm{U}_{1} \cos \left(\omega_{\mathrm{r}} \mathrm{t}\right) \\
& \mathrm{i}_{\mathrm{r}}(\mathrm{t})=\frac{\mathrm{U}_{1}}{\mathrm{Z}_{\mathrm{r}}} \sin \left(\omega_{\mathrm{r}} \mathrm{t}\right)
\end{aligned}
$$

where $\omega_{\mathrm{r}}=\frac{1}{\sqrt{\mathrm{L}_{\mathrm{r}} \mathrm{C}_{\mathrm{r}}}}$ and $\mathrm{Z}_{\mathrm{r}}=\sqrt{\frac{\mathrm{L}_{\mathrm{r}}}{\mathrm{C}_{\mathrm{r}}}}$ are the resonance angular frequency and characteristic impedance, respectively. If $U_{1}$ is higher than the input voltage $U_{g}$, capacitor voltage $u_{r}$ reverses becoming equal to $-U_{g}$ at instant $T_{1}$. This causes the turn on of diode $D_{1}$ ending this phase, whose duration is:

$\mathrm{T}_{01}=\frac{1}{\omega_{\mathrm{r}}} \mathrm{a} \cos \left(-\frac{\mathrm{U}_{\mathrm{g}}}{\mathrm{U}_{1}}\right)$

The value of current $i_{r}$ at the end of this interval is:

$\mathrm{I}_{\mathrm{r} 1}=\mathrm{i}_{\mathrm{r}}\left(\mathrm{T}_{01}\right)=\frac{\mathrm{U}_{1}}{\mathrm{Z}_{\mathrm{r}}} \sin \left(\omega_{\mathrm{r}} \mathrm{T}_{01}\right)=\frac{\mathrm{U}_{1}}{\mathrm{Z}_{\mathrm{r}}} \sqrt{1-\left(\frac{\mathrm{U}_{\mathrm{g}}}{\mathrm{U}_{1}}\right)^{2}}$

Interval $T_{12}=T_{2}-T_{1}$ [see Fig. 3b]. When $\mathrm{D}_{1}$ turns on, the capacitor voltage $u_{r}$ remains clamped to $-U_{g}$ while current $i_{r}$ decreases linearly to zero at instant $T_{2}$, thus turning off diodes $\mathrm{D}_{1}$ and $\mathrm{D}_{2}$ with a controlled di/dt. Current $\mathrm{i}_{\mathrm{r}}$ behavior is described by:

$\mathrm{i}_{\mathrm{r}}(\mathrm{t})=\mathrm{I}_{\mathrm{r} 1}-\frac{\mathrm{U}_{\mathrm{g}}}{\mathrm{L}_{\mathrm{r}}} \mathrm{t}$

while the interval duration is:

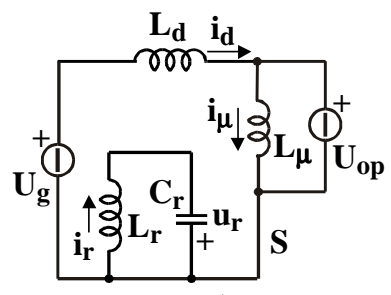

a)

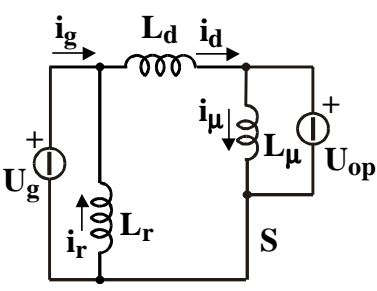

b)

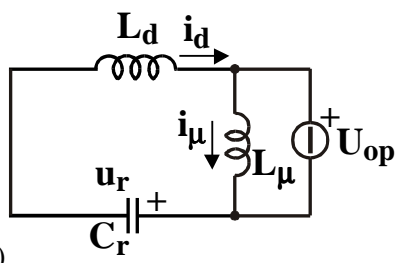

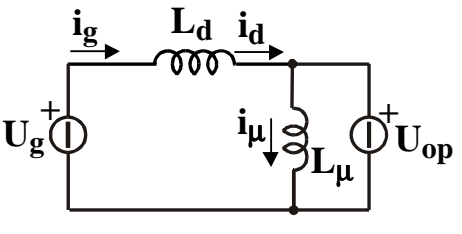

d)

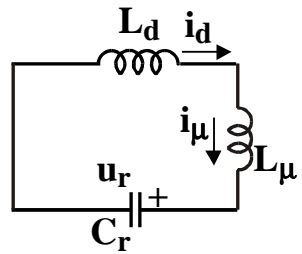

e)
Fig. 3 - Subcircuits corresponding to different intervals during a switching period. a) interval $\mathrm{T}_{01} ; \mathrm{b}$ ) interval $\mathrm{T}_{12} ; \mathrm{c}$ ) interval $\mathrm{T}_{23} ; \mathrm{d}$ ) interval $\mathrm{T}_{34} ; \mathrm{e}$ ) interval $\mathrm{T}_{45}$

$\mathrm{T}_{12}=\frac{\mathrm{L}_{\mathrm{r}} \mathrm{I}_{\mathrm{r} 1}}{\mathrm{U}_{\mathrm{g}}}$

Interval $T_{23}=T_{3}-T_{2}$ [see Fig. $3 c$ ]. This interval ends the switch on time while the snubber remains deactivated. During this phase as well as the previous one, the input inductor and magnetizing currents continue to increase linearly, following (2) and (3).

$\mathrm{T}_{23}=\mathrm{T}_{\mathrm{ON}}-\mathrm{T}_{01}-\mathrm{T}_{12}$

Interval $T_{34}=T_{4}-T_{3}$ [see Fig. 3d]. The switch turns off at instant $\mathrm{T}_{4}$ under zero voltage condition and its voltage rises following the same behavior of snubber capacitor voltage $\mathrm{u}_{\mathrm{r}}$, which resonates with the leakage inductance $\mathrm{L}_{\mathrm{d}}$. Their voltage and current waveforms are given by:

Initial conditions:

$\left\{\begin{array}{l}\mathrm{u}_{\mathrm{r}}(0)=-\mathrm{U}_{\mathrm{g}} \\ \mathrm{i}_{\mathrm{d}}(0)=\mathrm{I}_{\mathrm{d} 3}=\mathrm{i}_{\mathrm{d}}\left(\mathrm{T}_{03}\right)=\frac{\mathrm{U}_{\mathrm{g}}-\mathrm{U}_{\mathrm{op}}}{\mathrm{L}_{\mathrm{d}}} \mathrm{T}_{\mathrm{ON}}\end{array}\right.$

$\mathrm{u}_{\mathrm{r}}(\mathrm{t})=-\mathrm{U}_{\mathrm{op}}-\left(\mathrm{U}_{\mathrm{g}}-\mathrm{U}_{\mathrm{op}}\right) \cos \left(\omega_{1} \mathrm{t}\right)+\mathrm{Z}_{1} \mathrm{I}_{\mathrm{d} 3} \sin \left(\omega_{1} \mathrm{t}\right)$

$\mathrm{i}_{\mathrm{d}}(\mathrm{t})=\mathrm{I}_{\mathrm{d} 3} \cos \left(\omega_{1} \mathrm{t}\right)+\left(\frac{\mathrm{U}_{\mathrm{g}}-\mathrm{U}_{\mathrm{op}}}{\mathrm{Z}_{1}}\right) \sin \left(\omega_{1} \mathrm{t}\right)$

where $\omega_{1}=\frac{1}{\sqrt{\mathrm{L}_{\mathrm{d}} \mathrm{C}_{\mathrm{r}}}}$ and $\mathrm{Z}_{1}=\sqrt{\frac{\mathrm{L}_{\mathrm{d}}}{\mathrm{C}_{\mathrm{r}}}}$ are the resonance angular frequency and characteristic impedance, respectively. During this phase, the rectifier diode $D_{r}$ remains on, continuing the energy transfer from the source to the load. At the same time, the magnetizing current continues to increase under the action of the output voltage 
reflected to the primary side. This interval lasts until the transformer secondary current $i_{s}=\left(i_{d}-i_{\mu}\right) / n$ zeroes, causing the turn off of diode $\mathrm{D}_{\mathrm{r}}$, again with a controlled di/dt. Its duration can be calculated from the following equation:

$$
\begin{aligned}
\mathrm{i}_{\mathrm{d}}\left(\mathrm{T}_{34}\right) & =\mathrm{I}_{\mathrm{d} 3} \cos \left(\omega_{1} \mathrm{~T}_{34}\right)+\left(\frac{\mathrm{U}_{\mathrm{g}}-\mathrm{U}_{\mathrm{op}}}{\mathrm{Z}_{1}}\right) \sin \left(\omega_{1} \mathrm{~T}_{34}\right) \\
& =\mathrm{i}_{\mu}\left(\mathrm{T}_{\mathrm{ON}}+\mathrm{T}_{34}\right)=\hat{\mathrm{I}}_{\mu}
\end{aligned}
$$

The exact value for $\mathrm{T}_{34}$ can be computed only numerically. However, an approximated expression can be derived neglecting the magnetizing current in (13). The result is as follows:

$$
\mathrm{T}_{34} \approx \frac{1}{\omega_{1}}\left[\pi-\mathrm{a} \tan \left(-\frac{\mathrm{Z}_{1} \mathrm{I}_{\mathrm{d} 3}}{\mathrm{U}_{\mathrm{g}}-\mathrm{U}_{\mathrm{op}}}\right)\right]=\frac{1}{\omega_{1}}\left[\pi-\mathrm{a} \tan \left(\omega_{1} \mathrm{~T}_{\mathrm{ON}}\right)\right]
$$

where the definition of $\mathrm{I}_{\mathrm{d} 3}$ from (11) was used to derive the last expression. Note that $\frac{\pi}{2}<\omega_{1} \mathrm{~T}_{34}<\pi$.

The voltage $U_{2}$ across the resonant capacitor at instant $T_{4}$ is calculated from (12.a) and is given by:

$$
\begin{aligned}
\mathrm{U}_{2} & =\mathrm{u}_{\mathrm{r}}\left(\mathrm{T}_{34}\right) \\
& =-\mathrm{U}_{\mathrm{op}}-\left(\mathrm{U}_{\mathrm{g}}-\mathrm{U}_{\mathrm{op}}\right) \cos \left(\omega_{1} \mathrm{~T}_{34}\right)+\mathrm{Z}_{1} \mathrm{I}_{\mathrm{d} 3} \sin \left(\omega_{1} \mathrm{~T}_{34}\right)
\end{aligned}
$$

Interval $T_{45}=T_{5}-T_{4}$ [see Fig. 3e]. During this interval the snubber capacitor resonates with the whole transformer inductance $\mathrm{L}_{d}+\mathrm{L}_{\mu}$ bringing the magnetizing current to zero, thus resetting the transformer core. The initial conditions to be used are:

$$
\left\{\begin{array}{l}
\mathrm{u}_{\mathrm{r}}(0)=\mathrm{U}_{2} \\
\mathrm{i}_{\mathrm{d}}(0)=\mathrm{i}_{\mu}(0)=\frac{\mathrm{U}_{\mathrm{op}}}{\mathrm{L}_{\mu}}\left(\mathrm{T}_{\mathrm{ON}}+\mathrm{T}_{34}\right)=\hat{\mathrm{I}}_{\mu}
\end{array}\right.
$$

while voltage and current are given by:

$$
\begin{aligned}
& \mathrm{u}_{\mathrm{r}}(\mathrm{t})=\mathrm{U}_{2} \cos \left(\omega_{2} \mathrm{t}\right)+\mathrm{Z}_{2} \hat{\mathrm{I}}_{\mu} \sin \left(\omega_{2} \mathrm{t}\right) \\
& \mathrm{i}_{\mathrm{d}}(\mathrm{t})=\mathrm{i}_{\mu}(\mathrm{t})=\hat{\mathrm{I}}_{\mu} \cos \left(\omega_{2} \mathrm{t}\right)-\frac{\mathrm{U}_{2}}{\mathrm{Z}_{2}} \sin \left(\omega_{2} \mathrm{t}\right)
\end{aligned}
$$

where

$$
\omega_{2}=\frac{1}{\sqrt{\left(\mathrm{L}_{\mathrm{d}}+\mathrm{L}_{\mu}\right) \mathrm{C}_{\mathrm{r}}}}=\omega_{1} \sqrt{\frac{\alpha}{1+\alpha}}
$$

$\mathrm{Z}_{2}=\sqrt{\frac{\mathrm{L}_{\mathrm{d}}+\mathrm{L}_{\mu}}{\mathrm{C}_{\mathrm{r}}}}=\mathrm{Z}_{1} \sqrt{\frac{1+\alpha}{\alpha}}$ are the resonance angular frequency and characteristic impedance, respectively and $\alpha=\frac{\mathrm{L}_{\mathrm{d}}}{\mathrm{L}_{\mu}}$. Interval $\mathrm{T}_{45}$ can be computed by letting $\mathrm{i}_{\mathrm{d}}\left(\mathrm{T}_{34}\right)=0$.

$\mathrm{T}_{45}=\frac{1}{\omega_{2}} \mathrm{a} \tan \left(\frac{\mathrm{Z}_{2} \hat{\mathrm{I}}_{\mu}}{\mathrm{U}_{2}}\right)$

The voltage across $C_{r}$ at the end of this phase is equal to the initial voltage $\mathrm{U}_{1}$ considered at the beginning of the switching period, i.e.:

$$
\mathrm{u}_{\mathrm{r}}\left(\mathrm{T}_{45}\right)=\mathrm{U}_{2} \cos \left(\omega_{2} \mathrm{~T}_{45}\right)+\mathrm{Z}_{2} \hat{\mathrm{I}}_{\mu} \sin \left(\omega_{2} \mathrm{~T}_{45}\right)=\mathrm{U}_{1}
$$

Interval $T_{56}=T_{6}-T_{5}$. This phase, in which the load is fed only by the output capacitor, completes the switching period.

$$
\mathrm{T}_{56}=\mathrm{T}_{\mathrm{S}}-\mathrm{T}_{\mathrm{ON}}-\mathrm{T}_{34}-\mathrm{T}_{45}
$$

\section{VOLTAGE CONVERSION RATIO}

The approximated voltage conversion ratio $M$ can be derived from the equations describing the converter behavior and corresponding to the waveforms of Fig. 2 . In particular, the average (in a switching period) secondary current $\overline{\mathrm{i}}_{\mathrm{s}}=\frac{\overline{\mathrm{i}}_{\mathrm{d}}-\overline{\mathrm{i}}_{\mu}}{\mathrm{n}}$ is calculated and equated to the load current. In order to derive a closed form for $\mathrm{M}$, the approximated formula (14) for $\mathrm{T}_{34}$ was used under the assumption of a negligible magnetizing current as compared to the input inductor current $i_{d}$. The result is the following relation:

$$
\mathrm{M}=\frac{\mathrm{U}_{\mathrm{op}}}{\mathrm{U}_{\mathrm{g}}} \approx \frac{1}{1+\frac{2+\mathrm{R}_{\mathrm{LpN}} \alpha \omega_{1} \beta^{2}}{\mathrm{R}_{\mathrm{LpN}}\left(2+\theta_{\mathrm{on}}^{2}+2 \sqrt{1+\theta_{\mathrm{on}}^{2}}\right)}}
$$

where $\quad \theta_{\text {on }}=\omega_{1} \mathrm{dT}_{\mathrm{s}}, \quad \beta=\theta_{\text {on }}+\pi-\mathrm{a} \tan \left(\theta_{\text {on }}\right), \quad$ and $R_{L p N}=\frac{R_{L p} C_{r}}{T_{s}}=\frac{R_{L} C_{r}}{n^{2} T_{s}}$ is the normalized load resistance reflected to the primary side. An example of control characteristics, i.e the voltage conversion ratio as a function of the duty-cycle for different values of normalized load resistance $R_{L p N}$, is shown in Fig. 4 for the set of converter parameters listed in Table I: as we can see, just like any forward converter, there is a limited maximum duty-cycle due to the need of resetting the transformer (interval $\mathrm{T}_{45}$ in Fig. 2), together with a limited minimum duty-cycle in order to ensure a proper operation of the snubber circuit (interval $\mathrm{T}_{01}$ in Fig. 2). Last, but not least, the zero voltage condition poses further limitations on the converter operating point. All these aspects are covered in the following section.

Table I - Converter parameters used in Fig. 4

$$
\begin{array}{llll}
\mathrm{L}_{\mathrm{d}}=8 \mu \mathrm{H} & \mathrm{L}_{\mathrm{r}}=6.5 \mu \mathrm{H} & \\
\mathrm{L}_{\mu}=300 \mu \mathrm{H} & \mathrm{C}_{\mathrm{r}}=3 \times 4.7 \mathrm{nF} & \mathrm{n}=0.5 & \mathrm{~T}_{\mathrm{S}}=5 \mu \mathrm{s}
\end{array}
$$

\section{ZERO VOLTAGE CONDITION}

In this converter, the zero voltage turn off condition requires voltage $U_{1}$ to be higher than the input voltage $U_{g}$. This condition depends mainly on the inductive energy stored in input inductor $\mathrm{L}_{\mathrm{d}}$ at the end of the switch on time: as a consequence, the ZVS condition is lost at light load. Moreover, a minimum switch on time equal to interval $T_{01}$ is required to reverse the voltage $\mathrm{u}_{\mathrm{r}}$ up to $-\mathrm{U}_{\mathrm{g}}$. In order to derive this lower boundary, the same approximation used in deriving the voltage conversion ratio, i.e. utilization of (14), is used. First, let's express voltage $\mathrm{U}_{1}$ as a function of $\mathrm{M}$ and 


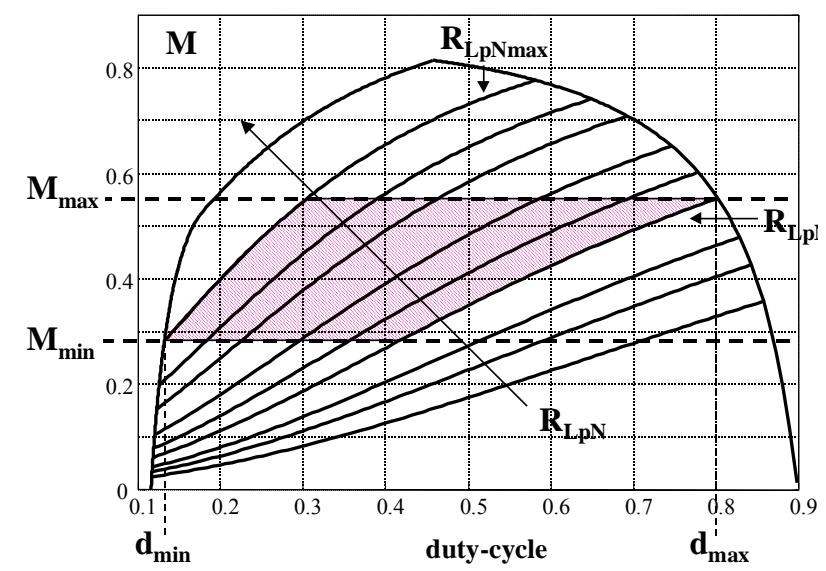

Fig. 4 - Voltage conversion ratio $\mathrm{M}$ as a function of duty-cycle for different values of normalized load resistance $\mathrm{R}_{\mathrm{LpN}}$

other converter parameters. Substituting (11) into (15) allows to derive $\mathrm{U}_{2}$ as follows:

$\mathrm{U}_{2}=\mathrm{U}_{\mathrm{g}}\left(-\mathrm{M}+(1-\mathrm{M}) \sqrt{1+\theta_{\mathrm{on}}^{2}}\right)$

Then, using (14), (16), (18) and (22) into (19) we find:

$\mathrm{U}_{1}=-\frac{\mathrm{U}_{\mathrm{g}}}{\mathrm{k}}$

where

$$
\mathrm{k}=-\frac{1}{\sqrt{\left(-M+(1-M) \sqrt{1+\theta_{\text {on }}^{2}}\right)^{2}+\alpha(1+\alpha)(M \beta)^{2}}}
$$

If $k>-1$ then $U_{1}>U_{g}$ the soft switching condition can be satisfied, and the minimum switch on time can be derived from (6) as:

$$
\mathrm{T}_{\text {ONmin }}=\frac{1}{\omega_{\mathrm{r}}} \cos ^{-1} \mathrm{k}
$$

The latter can be solved in numerical form for different values of the normalized load resistance $\mathrm{R}_{\mathrm{LpN}}$.

The limitation on the maximum switch on time, necessary to ensure DCM operation as well as proper transformer reset, can be found by letting interval $\mathrm{T}_{56}=0$ into (20). Then, we have:

$$
\mathrm{T}_{\mathrm{ON} \max }=\mathrm{T}_{\mathrm{S}}-\mathrm{T}_{34}-\mathrm{T}_{45}
$$

Using (16), (18) and (22) into (26) we obtain:

$$
\begin{aligned}
\theta_{\mathrm{ONmax}} & =\omega_{1} \mathrm{~T}_{\mathrm{S}}-\left[\pi-\operatorname{atan}\left(\theta_{\mathrm{ONmax}}\right)\right]+ \\
& -\sqrt{\frac{1+\alpha}{\alpha}} \operatorname{atan}\left[\frac{\beta \sqrt{\alpha(1+\alpha)}}{-1+\left(\frac{1}{\mathrm{M}}-1\right) \sqrt{1+\theta_{\mathrm{ONmax}}^{2}}}\right]
\end{aligned}
$$

An example of duty-cycle limitation given by (25) and (27) is shown in Fig. 5 in terms of boundary curves for the control characteristics. The same figure, knowing the minimum and maximum voltage conversion ratio, allows to identify the minimum and maximum normalized load resistances which still guarantee a soft commutation.
If diode $\mathrm{D}_{3}$ is removed to avoid its conduction losses, the converter behavior changes because now, during interval $\mathrm{T}_{56}$, the capacitor $\mathrm{C}_{\mathrm{r}}$ starts to discharge to the input in the resonant manner through $\mathrm{L}_{\mu}, \mathrm{L}_{\mathrm{d}}, \mathrm{L}_{\mathrm{r}}$ and $\mathrm{D}_{2}$. This reduces voltage $\mathrm{U}_{1}$ and adversely affects the soft switching condition, especially at high input voltage when the dutycycle is minimum.

\section{COMPONENT STRESSES}

In order to outline a reasonable design procedure, it is important to analyze the main component current and voltage stresses, highlighting their dependence on the different converter parameters.

Switch voltage stress. The maximum voltage across the switch occurs at the end of interval $\mathrm{T}_{45}$ when the voltage across the resonant capacitor reaches its maximum value, i.e.:

$\hat{\mathrm{U}}_{\mathrm{SW}}=\hat{\mathrm{U}}_{\mathrm{g}}+\hat{\mathrm{U}}_{1}=\hat{\mathrm{U}}_{\mathrm{g}}\left(1-\frac{1}{\mathrm{k}}\right)$

where (23) was used to derive the last term. The maximum occurs at maximum input voltage and load current.

Switch current stress. During $\mathrm{T}_{\mathrm{ON}}$ interval, the switch carries the sum of the input current $i_{d}$ and the resonant current $i_{r}$, i.e. from (2) and (5):

$\mathrm{i}_{\mathrm{SW}}(\mathrm{t})=\frac{\mathrm{U}_{\mathrm{g}}-\mathrm{U}_{\text {op }}}{\mathrm{L}_{\mathrm{d}}} \mathrm{t}+\frac{\mathrm{U}_{1}}{\mathrm{Z}_{\mathrm{r}}} \sin \left(\omega_{\mathrm{r}} \mathrm{t}\right)$

Its maximum can occur both during interval $\mathrm{T}_{01}$ or at the end of interval $\mathrm{T}_{\mathrm{ON}}$. In the first case the peak occurs approximately at the peak of the resonant current, i.e.:

$\hat{\mathrm{I}}_{\mathrm{SW} 1} \approx \frac{\mathrm{U}_{1}}{\mathrm{Z}_{\mathrm{r}}}+\frac{\mathrm{U}_{\mathrm{g}}-\mathrm{U}_{\mathrm{op}}}{\mathrm{L}_{\mathrm{d}}} \frac{\pi}{2 \omega_{\mathrm{r}}}$

so that the switch current stress can be expressed as:

$\hat{\mathrm{I}}_{\mathrm{SW}}=\max \left\{\hat{\mathrm{I}}_{\mathrm{SW} 1}, \frac{\hat{\mathrm{U}}_{\mathrm{g}}-\mathrm{U}_{\mathrm{op}}}{\mathrm{L}_{\mathrm{d}}} \mathrm{T}_{\mathrm{ON}}\right\}$

Diode $D_{1}$ voltage and current stresses. The maximum voltage across $\mathrm{D}_{1}$ occurs at the switch turn on and coincides with the switch voltage stress (28). Its maximum current can occur either at $T_{1}$, when it starts carrying the resonant current $\mathrm{i}_{\mathrm{r}}$, or during interval $\mathrm{T}_{34}$, when the input inductor current $i_{d}$ is flowing through it. From (7), and (12b) we can write:

$\hat{\mathrm{I}}_{\mathrm{D} 1}=\max \left\{\hat{\mathrm{I}}_{\mathrm{r} 1}, \hat{\mathrm{I}}_{\mathrm{d}}\right\}$

where

$\hat{\mathrm{I}}_{\mathrm{d}}=\sqrt{\hat{\mathrm{I}}_{\mathrm{d} 3}^{2}+\left(\frac{\hat{\mathrm{U}}_{\mathrm{g}}-\mathrm{U}_{\mathrm{op}}}{\mathrm{Z}_{1}}\right)^{2}}$

Diode $\mathrm{D}_{2}$ voltage and current stresses. The maximum voltage across $D_{2}$ occurs when $D_{1}$ is on, and is equal to the maximum input voltage, while its maximum current coincides with the peak of the resonant current $i_{r}$. 
Diode $D_{3}$ voltage and current stresses. The maximum voltage across $\mathrm{D}_{3}$ occurs at the end of interval $\mathrm{T}_{45}$ when the input inductor current zeroes, and is equal to the maximum voltage $\hat{U}_{1}$ across the resonant capacitor $C_{r}$, while its maximum current coincides with the peak of the input inductor current $\hat{\mathrm{I}}_{\mathrm{d}}$.

Diode $D_{r}$ voltage and current stresses. The maximum voltage across $D_{\mathrm{r}}$ occurs at the end of interval $T_{45}$ and is given by:

$\hat{\mathrm{U}}_{\mathrm{Dr}}=\mathrm{n} \hat{\mathrm{U}}_{1}\left(\frac{\mathrm{L}_{\mu}}{\mathrm{L}_{\mathrm{d}}+\mathrm{L}_{\mu}}\right)+\mathrm{U}_{\mathrm{o}}$

The $D_{r}$ current stress is given by the difference between the input inductor current $i_{d}$ and the magnetizing current. Neglecting the latter, the maximum current equals $\hat{I}_{d}$ (see (32b)).

\section{DESIGN CONSIDERATIONS}

From the analysis carried out in the previous sections, we have seen that the converter parameters must be chosen in order to ensure soft-switching as well as a proper transformer core reset in all the operating points of interest, i.e. in the desired input voltage and output current ranges. This has to be done taking into account also voltage and current stresses in the main devices. The curves reported in Fig. 5, showing the effect of different parameters on the soft-switching area in the control characteristics, help to made a first choice. From these curves we can made the following considerations:

- the magnetizing inductance can be chosen so as to meet the core needs without affecting too much the soft switching behavior;

- the input inductor $L_{d}$ strongly influences both minimum and maximum power achievable under soft commutations, and, consequently, it affects all the device current stresses;

- the resonant inductor $L_{r}$ value poses a limitation only on the minimum duty-cycle (i.e. minimum power at maximum input voltage) and has effect on switch and diodes $\mathrm{D}_{1}$ and $\mathrm{D}_{2}$ current stresses;

- the resonant capacitor $C_{r}$ is another key parameter strongly affecting the soft switching area and voltage $U_{1}$ value, which determines the voltage stress of many devices.

If the transformer parameters are known (magnetizing inductance $\mathrm{L}_{\mu}$ and leakage inductance $\mathrm{L}_{\mathrm{d}}$ ), then a possibile design procedure could be to select a $\mathrm{C}_{\mathrm{r}}$ value based on the maximum output power constraint, and the $\mathrm{L}_{\mathrm{r}}$ value to maintain the soft switching condition up to the desired minimum power.

\section{EXPERIMENTAL RESULTS}

A converter prototype, rated at $\mathrm{U}_{\mathrm{g}}=36 \div 48 \mathrm{~V}, \mathrm{U}_{\mathrm{o}}=12 \mathrm{~V}$ and $\mathrm{P}_{\mathrm{oN}}=50 \mathrm{~W}$ with the basic component values given by Table I, was developed. The transformer, built on a ETD34 core size, had a gap on one lateral leg plus few turns in series with the primary winding (located, with the secondary

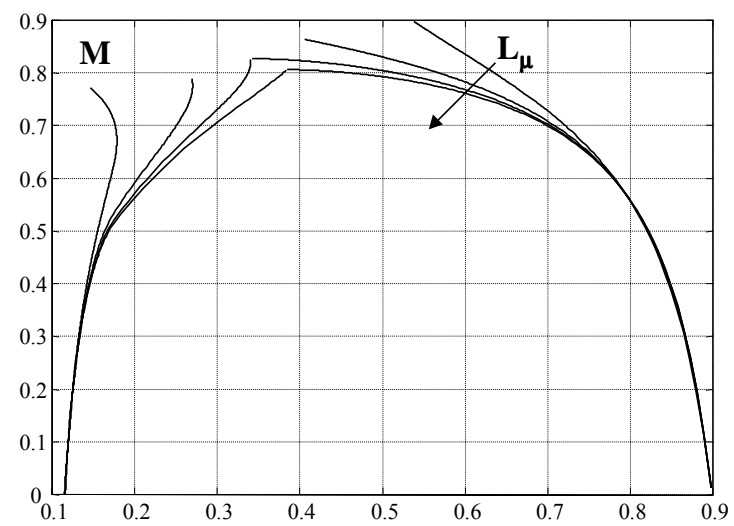

a)

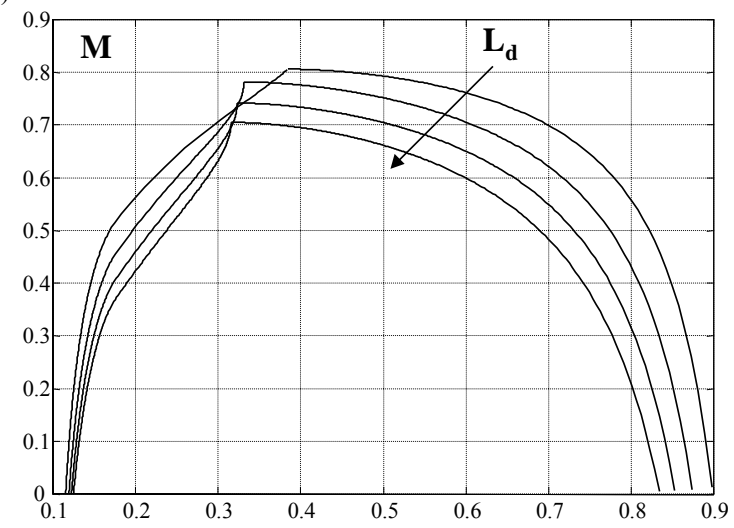

b)

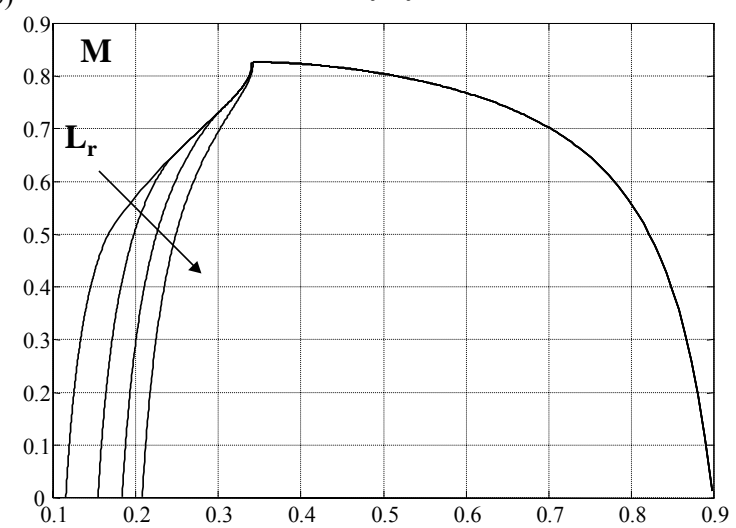

c)

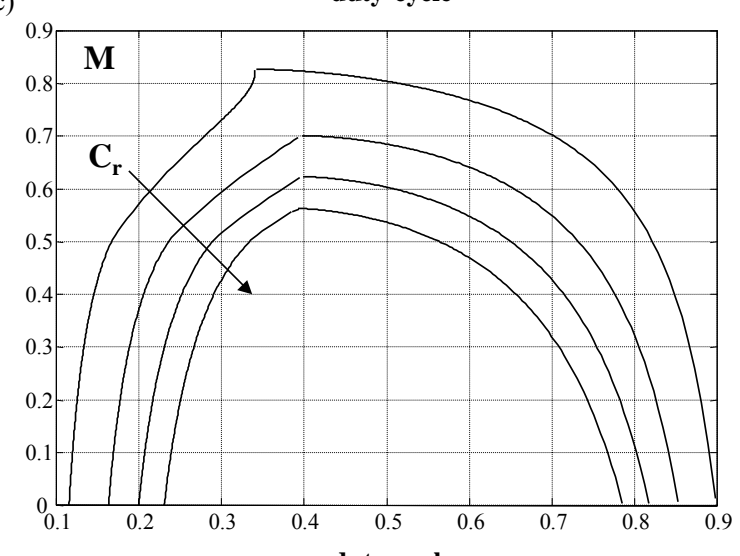

d)

Fig. 5 - Boundary curves at different converter parameter values; a) $\mathrm{L}_{\mu}=100 \div 400 \mu \mathrm{H} ;$ b) $\mathrm{L}_{\mathrm{d}}=8 \div 20 \mu \mathrm{H} ;$ c) $\mathrm{L}_{3}=6.5 \div 24 \mu \mathrm{H}$; d) $\mathrm{C}_{\mathrm{r}}=12 \div 48 \mathrm{nF}$; 
winding, on the ungapped central leg) in order to produce the desired input inductance $\mathrm{L}_{\mathrm{d}}$. Unfortunately, at the time of writing, the transformer was not optimized, giving rise to excessive power loss. The prototype was used to verify several theoretical results. Fig. 6 shows the main converter waveforms, which closely resemble the ones shown in Fig. 2. Note the step on the $u_{D S}$ waveform during the switch off time, revealing the end of interval $\mathrm{T}_{45}$. The voltage conversion ratio was then measured, giving the results shown in Fig. 7. As can be seen, the experimental data closely match the theoretical curves, especially at reduced output power, where the unity efficiency assumption is better verified.

\section{TOPOLOGY MODIFICATION AND FUTURE WORK}

The elimination of diode $\mathrm{D}_{3}$ from the converter topology greatly improves the overall efficiency, but also significantly modifies the converter's behavior. Therefore, the analysis outlined in Section II and III, is no longer valid. Nevertheless, the basic good properties of the converter are maintained. In particular, Fig. 8 shows how the converter waveforms modify after diode $\mathrm{D}_{3}$ is removed. It is possible to see the discharge of the resonant capacitor during the switch off interval. Anyway, at nominal output power, soft switching is maintained. In these conditions, the measured efficiency grows from 0.75 to 0.815 . A significant improvement can be achieved by optimizing the magnetic part of the converter, which is currently dissipating a significant amount of power. Just using an external pot core to build $\mathrm{L}_{\mathrm{d}}$ and removing the auxiliary winding on the transformer lateral leg improved the efficiency up to $85 \%$. This will be the object of future research activity.

\section{CONCLUSIONS}

A simple soft-switching forward DC-DC converter suitable for low power applications is presented. The converter uses a lossless passive turn-off snubber to provide zero voltage turn-off of the switch as well as transformer reset. Moreover, the converter operates in discontinuous conduction mode (DCM), which guarantees zero current turn on of the switch and allows to eliminate the inductive output filter. A detailed converter analysis supported by the main simulated waveforms is given, which highlights advantages and drawbacks of the topology. Experimental results verify and validate the theoretical analysis.

\section{REFERENCES:}

1. A. Elasser, D. A. Torrey, "Soft Switching Active Snubbers for DC/DC Converters," IEEE Transaction on Power Electronics, Vol.11, No.5, September 1996, pp.710-722.

2. A. A. Pereira, L. C. de Freitas, J. L. Andres, "A Self-Resonant PWM Forward Converter," IECON Conf. Proc., 1994, pp. 170-175.

3. P. Dias, A. A. Pereira, J. B. Vieira Jr, V. J. Farias, L. C. de Freitas, "An Improved Self-Resonant PWM Forward Converter," APEC Conf. Proc., 1998, pp. 620-625.

4. Y. Xi, P. K. Jain, Y. F. Liu, R. Orr, "A Self Core Reset and Zero Voltage Switching Forward Converter Topology," IEEE Transaction on Power Electronics, Vol.15, No.6, November 2000, pp.1192-1203.

5. T. Ninomiya, T. Tanaka, K. Harada, "Analysis and Optimization of a Nondissipative LC Turn-Off Snubber," IEEE Trans. on Power Electronics, vol. 3, No. 2, April 1988, pp. 147-156.

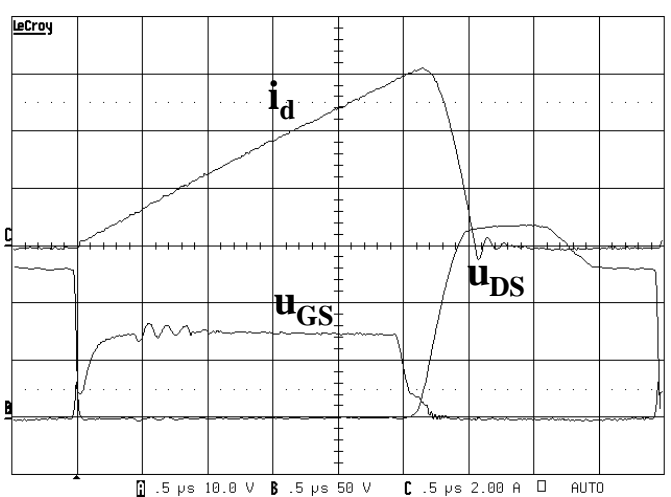

Fig. 6 - Measured main converter waveforms @ $\mathrm{U}_{\mathrm{g}}=42 \mathrm{~V}, \mathrm{U}_{\mathrm{o}}=12 \mathrm{~V}$, $\mathrm{P}_{\mathrm{o}}=50 \mathrm{~W}$, with diode $\mathrm{D}_{3}$

$i_{\mathrm{d}}: 2 \mathrm{~A} / \mathrm{div}, \mathrm{u}_{\mathrm{DS}}: 50 \mathrm{~V} / \mathrm{div}, \mathrm{u}_{\mathrm{GS}}: 10 \mathrm{~V} / \mathrm{div}$

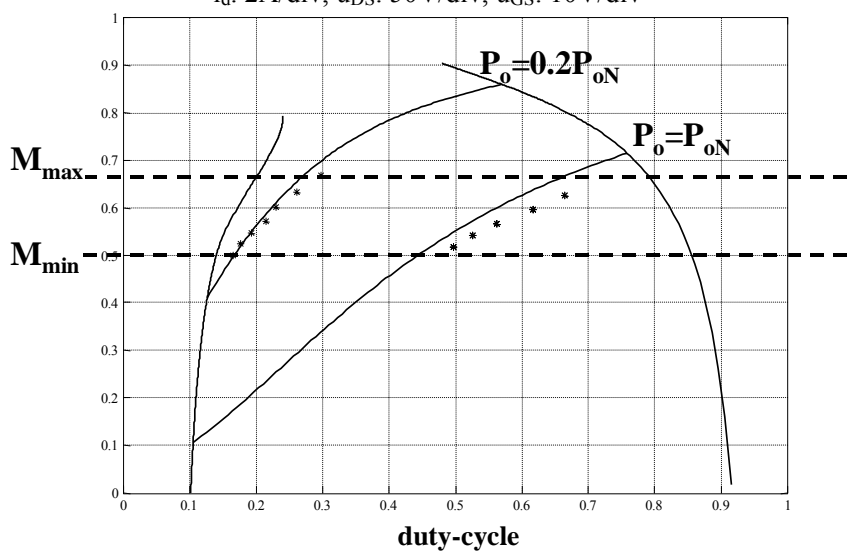

Fig. 7 - Comparison between calculated and measured voltage conversion ratio as a function of duyu-cycle for two different power levels

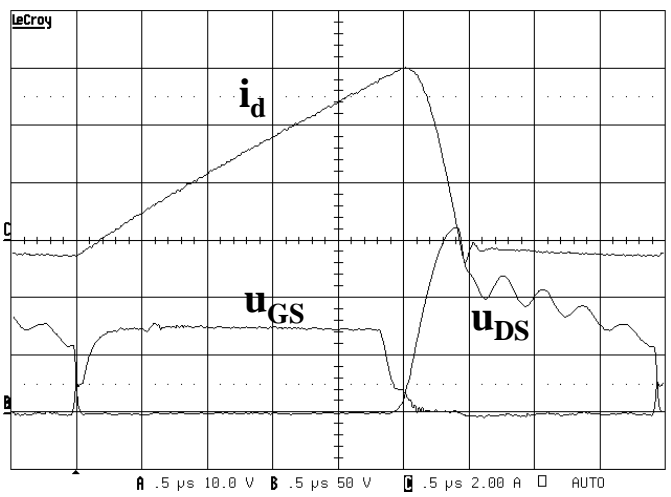

Fig. 8 - Measured main converter waveforms @ $\mathrm{U}_{\mathrm{g}}=42 \mathrm{~V}, \mathrm{U}_{\mathrm{o}}=12 \mathrm{~V}$, $\mathrm{P}_{\mathrm{o}}=50 \mathrm{~W}$, without diode $\mathrm{D}_{3}$ $i_{\mathrm{d}}: 2 \mathrm{~A} / \mathrm{div}, \mathrm{u}_{\mathrm{DS}}: 50 \mathrm{~V} / \mathrm{div}, \mathrm{u}_{\mathrm{GS}}: 10 \mathrm{~V} / \mathrm{div}$ 